\title{
O princípio da isonomia e a diferença salarial entre gêneros
}

\author{
Ana Paula Batista Guimarães de Oliveira e Daniela Bertotti² \\ Recebido em: 06/05/2013. Aprovado em: 21/06/2013. Disponibilizado em: 26/06/2013
}

1. Ana Paula Batista Guimarães de Oliveira é estudante do $5^{\circ}$ semestre de Direito das Faculdades Integradas Campos Salles e graduada em Administração de Empresas pela Universidade São Judas Tadeu.

2. Daniela Bertotti é professora no curso de Direito das Faculdades Integradas "Campos Salles". Doutoranda em Direito pela Pontifícia Universidade Católica de São Paulo

\section{Resumo}

O presente artigo apresenta a importância do Princípio da Isonomia no âmbito legal, em especial no Direito do Trabalho no que se refere ao salário dos empregados de gêneros distintos que exercem atividade profissional em condições semelhantes. O Princípio da Isonomia visa dois objetivos: propiciar a garantia individual contra perseguições e tolher favoritismos. A Constituição Federal do Brasil adotou, como um de seus sustentáculos, o Princípio da Isonomia. Sua importância é tal que a própria legislação não pode ser editada em desconformidade com esse princípio. Não só a Constituição Federal como também as leis específicas direcionadas às relações do trabalho, possuem normas que visam impedir a prática da diferenciação salarial baseada exclusivamente na discriminação do gênero. No desenvolvimento histórico-social do trabalho da mulher encontra-se a origem e os motivos pelos quais a diferença salarial ainda é praticada atualmente. Por meio do processo judicial a trabalhadora pode reivindicar a equiparação salarial. Sendo que para isso a autora da ação tem o ônus da prova e deve suprir os seguintes requisitos exigidos no artigo 461 da CLT: função semelhante, de mesmo valor, mesma produtividade, mesma perfeição técnica, simultaneidade na prestação de serviços, mesmo empregador, mesma localidade; que o empregado ao qual se equipara. A isonomia será alcançada por meio de um processo de análise dos efeitos da desigualdade material na vida cotidiana das mulheres e dos homens. É necessária a avaliação crítica da legislação com vistas à implementação de políticas públicas e programas específicos de promoção à igualdade. Trata-se de avaliar as preocupações e as experiências das mulheres e dos homens desde a elaboração, acompanhamento até avaliação dessas políticas e programas, em todas as esferas políticas, jurídicas e sociais; de modo a assegurar vantagens e oportunidades iguais para mulheres e homens e evitar que a desigualdade seja perpetuada.

Palavras-chave: Princípio da isonomia; Equiparação salarial; legislação. 


\section{Abstract}

The present article presents the importance of the principle of isonomy in legal framework, in particular in the area of labor law as regards the wages of employees of distinct genera that exercise professional activity in similar conditions. The principle of isonomy aims to two objectives: provide the individual guarantee against persecution and complicate favoritism. The Federal Constitution of Brazil has adopted, as one of its pillars, the principle of isonomy. Its importance is such that the legislation itself cannot be edited in conformity with this principle. Not only the Federal Constitution as well as the specific laws directed labor relations, have rules that are intended to prevent the practice of wage differentiation based exclusively on gender discrimination. The historical-social development of women's work is the origin and the reasons for the wage gap is still practiced today. Through the judicial process a worker can claim an equal salaries. It is for this reason that the author of the action has the burden of proof and must meet the following requirements in Article 461 of the CLT: similar function, of the same value, the same productivity, same technical perfection, concurrency in the provision of services, same employer, same locality; that the employee to which matches. The isonomy will be achieved by means of a process of analysis of the effects of material inequality in the daily life of women and men. It is necessary for the critical evaluation of the legislation with a view to the implementation of public policies and specific programs to promote equality.

Keywords: Principle of isonomy, Equal salaries, Legislation. 


\section{Introdução}

Todos são iguais perante a lei, prescreve a Constituição Federal. Essa afirmação tem como base o Princípio da Isonomia, entende-se que esse princípio não se restringe a equiparar os cidadãos diante da norma posta, mas principalmente que a própria lei não pode ser elaborada em desconformidade com a isonomia. (MELLO, 2010, p. 9)

O Direito do Trabalho, que bebe da fonte constitucional, tem dela seus princípios como alicerce. As fontes do Direito do Trabalho são: a Constituição, as leis, atos do poder executivo, sentença normativa, jurisprudência, doutrina, convenções e acordos coletivos, regulamentos de empresa, disposições contratuais, usos e costumes e as normas internacionais (MARTINS, 2008, p 38).

Mas como discorrer sobre o princípio $\mathrm{da}$ isonomia e as leis que dela nascem, sem expor sua eficácia na vida cotidiana. Entre as divergências entre teoria e prática, verifica-se um assunto que há muito tempo acompanha as relações sociais, independente do país, independente da época. É um fator profundamente enraizado em nossa cultura, desde o surgimento do trabalho remunerado. É a diferença salarial entre gêneros.

Como discorrer sobre o princípio da isonomia e as leis que dela emanam, sem expor sua eficácia na vida cotidiana? Entre as divergências entre teoria e prática, verifica-se um assunto que há muito tempo acompanha as relações sociais, independente do país, independente da época. É um fator profundamente enraizado em nossa cultura, desde o surgimento do trabalho remunerado, trata-se, pois, da diferença salarial entre gêneros.
Embora nas últimas décadas a participação das mulheres no mercado de trabalho venha crescendo, elas ainda estão em condições desiguais. Pesquisas ${ }^{1}$ apontam que apesar de ocorrer um aumento da inserção da mulher no ambiente de trabalho, ela ainda recebe salários menores.

Por que o trabalho masculino é mais valorizado que o feminino? Qual é a origem dessa discriminação? Origem histórica, social, cultural? Quais são os critérios utilizados para diferenciação salarial legítima? Há discriminação ocupacional entre gêneros? Quais são os requisitos para a equiparação salarial? Quais as leis que amparam o discriminado? Como ocorre o levantamento de provas? Qual a pena aplicada aos empregadores que infringem a isonomia salarial? E, acima de todas essas questões, por que o princípio da isonomia, tão ventilado pela ONU, OIT, Constituição Federal, Direito do Trabalho, ainda não é plenamente eficaz?

Ao longo do texto procuraremos responder essas perguntas, com base em análise de doutrina, pesquisas, legislação e jurisprudência.

\section{O princípio da isonomia}

Para Aristóteles havia duas formas de igualdade. Uma mais evidente ou igualdade aritmética (por exemplo: dar a um indivíduo o que lhe pertence); outra, proporcional, a igualdade dita geométrica, por exemplo: dar ao indivíduo o equivalente ao seu esforço (ARISTÓTELES, 1984, p. 324) As duas formas de igualdade objetivam alcançar a

\footnotetext{
${ }^{1}$ SEADE disponível em $<$ http://www.seade.gov.br/produtos/mulher/index .php?bole=10>; DIEESE disponível em <http://www.dieese.org.br/analiseped/2012/2012 pedmulhersao.pdf >>; Inep/ MEC disponível em $<$ http://www.publicacoes.inep.gov.br/detalhes.asp ?pub=4084>
} 
justiça. A primeira, a igualdade aritmética, é própria da justiça comutativa, aquela que rege as relações entre seres humanos iguais na sua condição. (MONTORO, 2006, p. 203) A segunda, a geométrica, é refere-se à justiça distributiva, justiça social, que distribui ou retribui as contribuições entre o todo e as partes, ou seja, a sociedade e os seres humanos que a integram, em função das diferenças entre estes. (MONTORO, 2006, p. 237).

Entre os juristas, Kelsen em "O problema da justiça”, sustenta que todos os indivíduos iguais devem ser tratados igualmente se as circunstâncias externas também forem iguais e quando os indivíduos e as circunstâncias externas forem desiguais, dever ser tratados desigualmente. (KELSEN, 1998, p. 37). Devido sua importância no ordenamento jurídico, a Constituição Federal brasileira prescreve no art. $5^{\circ}$ caput: "Todos são iguais perante a lei, sem distinção de qualquer natureza", sendo inviolável o direito à igualdade.

A Declaração Universal dos Direitos Humanos, promulgada pela Organização das Nações Unidas em 1948, também reconhece a importância da igualdade quando cita em seu artigo $1^{\circ}$ : "Todos os homens nascem livres e iguais em dignidade e direitos".

O destinatário da cláusula constitucional da igualdade é o legislador, e em consequência disso, a legislação. A lei visa o tratamento igualitário dos indivíduos, ou seja, ela não deve ser fonte de vantagens para uns e exclusão para outros, mas sim, a ferramenta reguladora da vida social equânime.

O princípio da igualdade deve ser redimensionado, para Oscar Vieira, em sua opinião esse princípio exige que as pessoas sejam tratadas com igual respeito e consideração, porém quando tem necessidades diferentes, diferente também deverá ser o tratamento dispensado as elas. (VIEIRA, 2006, p. 283)

A isonomia é o princípio que tem duplo objetivo, são eles: propiciar garantia individual contra perseguições e impedir favoritismos (MELLO, 2010, p. 23).

\section{A igualdade entre gêneros}

O constituinte no artigo $5^{\circ}$, inciso I especificou de maneira clara a abrangência de sua determinação: "homens e mulheres são iguais em direitos e obrigações, nos termos desta Constituição".

Ressalte-se ainda 0 art. $7^{\circ}$ nos incisos XXX e XXXI, nos quais a Constituição veda a diferença de salários, de exercício de funções, ou de critério de admissão por motivo de gênero, idade, cor, estado civil ou deficiência.

Contudo, há duas hipóteses de tratamento diferenciado entre as pessoas, sem que isso represente violação ao princípio da isonomia.

A primeira refere-se a situações previstas na própria constituição. Como exemplo o art. 143, \ $1^{\circ}$ da Constituição Federal, dispõe sobre a exclusão de mulheres e eclesiásticos do serviço militar obrigatório em tempo de paz, e também no art. 40 inciso III da Constituição Federal em que se refere ao tempo de contribuição para aposentadoria, menor para as mulheres do que para os homens.

A segunda hipótese está ligada às ações afirmativas, também conhecidas como "discriminações positivas", que visam equiparar as desigualdades e proteger as minorias contra qualquer forma de discriminação.

A expressão ação afirmativa, utilizada pela primeira vez numa ordem executiva federal norte-americana em 1965, passou a 
significar, desde então, a exigência de favorecimento de algumas minorias socialmente inferiorizadas e juridicamente desigualadas, por preconceitos arraigados culturalmente e que precisavam ser superados para que se atingisse a eficácia da igualdade preconizada e assegurada constitucionalmente pelos direitos fundamentais. (ROCHA, Carmem L.A. Ação Afirmativa: o conteúdo democrático do princípio da igualdade jurídica. Biblioteca Digital do Senado Federal, no 131, jul/set 1996, p. 285. Disponível em: <http://www2. senado.gov.br/bdsf/item/id/176462>

Acesso em 06 dez.2012).

Ações afirmativas podem ser vistas sob duas óticas: por meio do prisma social, as ações afirmativas são políticas públicas, visando reduzir as desigualdades sociais, buscam dar a grupos discriminados uma situação equivalente - igual - a de outros não discriminados. Por meio do prisma jurídico, tais políticas importam em estabelecer tratamento diferente - desigual a tais grupos, mas sem violar o princípio de isonomia. (artigo da $\mathrm{OAB}$ escrito pelo Professor Doutor Titular de Direito Constitucional da USP Manuel Gonçalves Ferreira Filho Aspectos jurídicos das ações afirmativas).

Por exemplo: não se pode dispensar o mesmo tratamento a um homem e a uma mulher em um teste de aptidão física para ingresso na força policial, tendo em vista que no quesito força física, homens e mulheres não são iguais, e devem ter tratamento diferenciado. (ALKMIM, 2009, p.379)

Outro exemplo observa-se nas filas de banco onde o tratamento dispensado a uma gestante é diferente do tratamento dispensado a um homem jovem, se objetiva tratá-los com respeito e consideração, devese então tratá-los diferenciadamente, visto a necessidade física que os difere. "O princípio da igualdade passa a se apresentar, paradoxalmente, como o princípio que determina a diferença legítima de tratamento que devo a cada pessoa, em face de diferenças específicas." (VIEIRA, 2006, p. 285).

\section{A mulher e o trabalho}

Quando os fabricantes ingleses, imensamente enriquecidos pelas máquinas recentes, vieram queixar-se a Pitt e disseram: Não aguentamos mais, não estamos ganhando o suficiente! , ele deu uma resposta pavorosa que pesa contra a sua memória: "Empregai as crianças."...Quem fala mulher, fala criança; em cada uma delas...uma família é destruída. (MICHELET, 1995, p.14)

A Revolução Industrial foi, sem dúvida, um marco na história do trabalho da mulher. Para Jules Michelet, um escritor francês do século XIX, ver uma mulher numa fábrica era um espetáculo bárbaro, pois a privava de ser a felicidade do homem e de sua própria felicidade com a maternidade. $O$ termo "operária" para Michelet tinha conotação ímpia e sórdida. (MICHELET, 1995, p. 14)

Compreende-se melhor essa época estudando-se o que levou a mulher a trabalhar fora de casa. Em seu livro intitulado "La Femme" Michelet discorre sobre o que levou a mulher a trabalhar nas fábricas, e chega à conclusão que os fabricantes ingleses são os responsáveis. Para ele, dois acontecimentos mudaram o destino da mulher na Europa, segundo sua argumentação, a mulher só exercia o ofício de fiar e costurar, e isso dentro do lar, propiciando a criação dos filhos e os cuidados do lar, porém com a invenção das máquinas o trabalho manual foi substituído ${ }^{2}$.

\footnotetext{
${ }^{2}$ Para Michelet os efeitos desse progresso são cruéis para a espécie humana. Ele estava vivendo uma época de transição, a tradição era
} 
A máquina de linho suprimiu a fiandeira assim como a máquina de costura suprimiu a costureira. (MICHELET, 1995, p. 21)

Antes disso, vida no campo era resumida da seguinte maneira: o homem casava-se para ter para si uma trabalhadora, para ajudá-lo nas tarefas. Era comparada a um escravo. O homem escolhia a mulher de menor apetite e pequena com a ideia de que terá menos fome. Ela trabalhava com ele no campo e também em casa, o homem tinha descanso, ela não. Ele surrava sua mulher, mesmo grávida e ela tinha que suportar o duplo sofrimento, no calor ou no frio. Muitas adoeciam e morriam, sendo assim não seria uma crueldade as mães terem ido para cidade, desejar uma vida menos sofrida para as filhas nas fábricas. (MICHELET, 1995, p. 18)

Naquela época, o homem ganhava cinco vezes mais que a mulher. Devido à pobreza nos campos, as mulheres migraram para as cidades e se sujeitavam a um salário menor que $\mathrm{o}$ dos homens para não morrerem de fome. (MICHELET, 1995, p. 16 e 17)

Os homens, no século XIX, faziam greve para exigir seus direitos, já à mulher era negado esse procedimento, isso contribuiu para que o salário da mulher estagnasse ao passo que o salário dos homens aumentava devido aos acordos sindicais. (MICHELET, 1995, p. 22)

paternalista, onde o homem era o chefe de família e deveria trabalhar para suprir as necessidades do lar; à mulher cabia o cuidado do lar e a educação dos filhos. Porém com a Revolução Industrial, e a oportunidade de produzir muito a um preço reduzido, a demanda aumentou e a necessidade de trabalhadores estava cada vez maior, os homens não supriam todo o contingente, e foi necessário para alimentar as fábricas, cada vez mais faminta de operários, empregar crianças e mulheres, com um preço inferior ao dos homens, visto que eram relativamente incapazes (MICHELET, 1995, p. 15)
Quanto ao salário inferior ao do homem Michelet justifica alegando que o homem consegue exercer cargo que exige força, e de maior valor, porém as mulheres, como seres mais frágeis ficavam doentes facilmente. Pois elas, segundo Michelet, não podem trabalhar muito tempo sentadas, nem muito tempo de pé, porém ele considera o trabalho doméstico saudável, pois garantia à mulher, no desenvolvimento de seus afazeres domésticos, ficar sempre em movimento. (MICHELET, 1995, p. 23)

A história do trabalho das mulheres é bem diferente da história do trabalho dos homens em muitos aspectos, porém o desenvolvimento é similar. Tal como os homens, as mulheres conheceram sucessivamente a escravatura, a servidão, o artesanato, a aparição da burguesia comerciante, a manufatura, a industrialização, as lutas operárias pelo melhoramento das condições de trabalho, horário e salário. Contudo, a história social dos trabalhadores evidencia as profundas diferenças que sempre existiram e ainda existem entre homens e mulheres.

As mulheres eram marginalizadas, pela condição a qual a sociedade a imputava, Evelyne Sullerot (1968), feminista francesa nascida em 1924, discorreu sobre os motivos pelos quais as mulheres chegavam, sempre, com atraso, nas etapas da história social. Para a autora o primeiro argumento é o da natureza: na sociedade patriarcal $O$ estabelecimento das distinções assegurava, sobretudo ao homem, exclusividades que o outro sexo não poderia disputar-lhe. A natureza, assim decidiu que a mulher geraria os filhos, alimentaria o bebê e seria mais fraca fisicamente que o homem. Destas observações que vão resultar nas divisões de tarefas, as tidas como mais leves para as mulheres, e as que necessitassem de mais força e resistência (consequentemente as mais valorizadas) para o homem. (SULLEROT, 1968, p. 22). 
O segundo motivo da diferenciação do trabalho feminino teve origem no antigo Egito e se manteve ao longo dos séculos, até hoje: os homens trabalhavam fora, e as esposas de homens livres faziam serviços domésticos. (SULLEROT, 1968, p. 28). O autor justificou plenamente esta situação invocando a vontade divina: "Os deusas criaram a mulher para as funções domésticas, o homem para todas as outras. Os Deuses a puseram nos serviços caseiros, porque ela suporta menos bem o frio, o calor e a guerra." Ele põe, na boca de Sócrates, estas afirmações que as artes aplicadas perderam o prestígio e o governo não lhes dedica a menor atenção, pois minam o corpo, forçando essas pessoas a ficar em casa, notando-se que quando o corpo é efeminado, as almas perdem sua energia. (Economiques, VII apud SULLEROT, 1968, p. 29).

Isto para citar que há certa maneira de viver, dentro de casa, que diminui a energia, e esta maneira de viver deve ser da mulher, pois é considerada como a mais frágil. Conclui-se daí que nada de grande pode ser realizado pela mulher. De qualquer forma, as coisas estão ligadas indissoluvelmente, e as tarefas de valor da sociedade grega, e de outras sociedades posteriores construir-se-ão fora de casa, mostrando seu desprezo por quem fica trabalhando em casa.

O terceiro motivo pelo qual Sullerot (1968) defende como causa do desprezo do trabalho da mulher é à sombra da prostituição. $O$ homem desejava livrar a vulnerável mulher, antes de tudo, do perigo das influências de fora de casa, sobretudo dos perigos sexuais. Quem trabalhava fora proclamava, dessa forma, a sua vulnerabilidade econômica. $\mathrm{Na}$ Antiguidade e durante a Idade Média, os ateliers de servas e operárias eram considerados antecâmaras da prostituição. A escrava, a serva, a criada e, mais tarde, a operária, ficavam à disposição do mestre. (SULLEROT, 1968, p. 32). As corporações femininas depois se esforçarão para afastar o espectro da prostituição.

Desde a origem dos tempos a prostituição se tornou o refúgio das moças pobres para conseguirem meios de subsistência. A prostituição foi o argumento sempre invocado para não respeitar $\mathrm{O}$ trabalho feminino que, diziam, fatalmente conduzia para ela. Teria sido sim possível usar o trabalho fora do lar como um antídoto da prostituição, mas para isso, seria então necessário pagar à mulher operária tanto quanto ao homem, e não aceitar a confusão entre operária e prostituta (SULLEROT, 1968, p. 33).

Uma das justificativas para a desigualdade de salários entre gêneros é a de que a mulher tem menos necessidades. $\mathrm{Na}$ Inglaterra no século XIX essa ideia parecia normal, mesmo que homem e mulher fizessem o mesmo trabalho com o mesmo rendimento. Esta desigualdade era regra em toda parte, as mulheres ganhavam cerca de $40 \%$ do salário pago ao homem (SULLEROT, 1968, p. 94). Além da justificativa de que a mulher tinha menos necessidades, os donos de fábrica defendiam sua prática alegando também que elas estavam acessíveis a poucas carreiras, por falta de formação, e que eram sustentadas pelo marido, e as indústrias que empregavam mulheres eram pouco mecanizadas, constituindo a mão de obra a quase totalidade do preço de custo. Cada um dos argumentos foi refutado posteriormente pelos movimentos feministas (SULLEROT, 1968, p. 94).

Devido a esse evidente problema, muitas mulheres se passaram por homens para receber um salário compatível. Uma mulher, empregada numa tipografia pediu para passar a trabalhar na oficina de composição, onde o salário era quatro vezes maior do que ganhava. Foi-lhe recusado. Então, cortou o cabelo, comprou roupas de 
homem e, dois dias mais tarde, foi contratada para trabalhar onde pretendia, pelo salário desejado, pelo mesmo empregador, que não a reconheceu. (SULLEROT, 1968, p. 97). Com crises e desemprego cada vez maior, os empregadores por vezes aproveitavam da situação para contratar mulheres por um salário evidentemente menor que o pago aos homens, e utilizavam desse argumento contra os trabalhadores homens, se estes tivessem pretensão de pedir aumento de salário ou diminuição das horas de trabalho.

Durante o decorrer da história, verificamos em todos os países a participação cada vez maior das mulheres no mercado de trabalho. A história do trabalho da mulher passou, e ainda passa, por transformações. Porém em comparação ao homem as mulheres ainda recebem um salário relativamente inferior, e tem dificuldade de alcançar cargos de liderança, apesar de atualmente estar comprovado que as mulheres estudam mais. Durante muito tempo defendeu-se que a diferença de salário entre a mulher e o homem ocorria devido à falta de preparação das mulheres e sua falta de estudos, porém as pesquisas indicam que as mulheres estudam em média quatro anos a mais que o homem, mas seu salário ainda é comparativamente menor.

\section{As transformações do trabalho feminino no Brasil}

No Brasil, nos séculos XVII e XVIII a mulher passou pelo que Léa Calil denomina como "Era da Exclusão", as mulheres de classe mais abastadas eram treinadas para cuidar do lar e educar os filhos. As menos afortunadas viúvas ou pobres faziam doces por encomenda, arranjos de flores, bordados ou davam aulas de piano para assim sustentar a numerosa prole. Entretanto, essas atividades não eram bem vistas socialmente. Tornavam-se alvo de maledicência por parte de homens e mulheres (CALIL, 2000, p. 18).

A Revolução Industrial transformou o mundo, pois com a descoberta de novas tecnologias mecânicas e barateamento das mais diversas máquinas - que as tornou acessíveis à grande maioria dos industriais a força física dos homens deixa de ser requisito para o trabalho nas fábricas, e se abriram as portas para as mulheres e crianças, que por sua "condição inferior", comprovada por estudos do médico Cesare Lombroso (1835-1909), recebiam salários significativamente inferiores aos pagos aos homens adultos (CALIL, 2000, p. 24).

No campo brasileiro não era diferente: as mulheres e as crianças que auxiliavam em colheitas e plantio eram consideradas meia enxada - recebendo metade do valor pago proporcionalmente ao homem, que era considerado como uma enxada inteira. Porém é interessante observar que produtivamente não diferiam (CALIL, 2000, p. 24).

A situação da trabalhadora nos primórdios da industrialização no Brasil era ruim, mal ganhava o mínimo necessário para seu próprio sustento, os empregadores preferiam contratar as mulheres e crianças, pois essa mão de obra custava em média $30 \%$ menos que a mão de obra do homem adulto (CALIL, 2000, p. 26).

Até o início do século XX a mulher trabalhadora estava excluída de proteção por parte do Estado, visto que a sociedade tinha por costume o preconceito dominante de que a rua, o espaço público, não era lugar para a mulher que estivesse desacompanhada. 


\section{A participação da mulher no mercado de trabalho}

A participação das mulheres no mercado de trabalho sempre foi inferior a dos homens. Ao homem a sociedade sempre atribuiu a tarefa de provedor, à mulher cabia a tarefa de cuidar do lar e dos filhos, por isso, em relação aos homens a proporção de mulheres no mercado de trabalho sempre foi inferior.

Não somente no Brasil, mas em todo o mundo, as mulheres se empenharam mais nos afazeres do lar do que em trabalhar fora. Quando o faziam, dedicavam-se a tarefas que podem ser associadas às tarefas do lar: cuidar de crianças ou educá-las, realizar serviços de limpeza, cozinha, ou atuar em profissões menos qualificadas na área da saúde. (DIEESE, 2001, p. 103).

Ao longo do século XX o desafio das mulheres foi abrir novos espaços para a atuação profissional em todas as áreas.

Esse desafio implica numa mudança cultural profunda, em todos os países, alguns com maior intensidade outros com menor intensidade. Cada vez mais mulheres passaram a ingressar no mercado de trabalho. Seja por realização, necessidade de compor a renda familiar ou a obrigação de assumir a responsabilidade total da família pelo desemprego ou ausência do cônjuge, são alguns dos fatores que contribuíram para que ao longo das últimas décadas do século $\mathrm{XX}$, a taxa de participação feminina aumentasse muito. (DIEESE, 2001, p. 104).

Em 1997 nos países desenvolvidos a taxa de participação feminina era o equivalente a $44 \%$ da população ativa, segundo o relatório das Nações Unidas para o desenvolvimento (PNUD). Deve-se considerar que essa taxa é diferente em cada país. No começo da década de 90 , nos países escandinavos, nos Estados Unidos e Canadá, as mulheres representavam praticamente a metade do PEA (População Economicamente Ativa). Nos países árabes, no entanto, só $25 \%$ das mulheres estava no mercado de trabalho. A tendência em todos os casos é de crescimento. (DIEESE, 2001, p. 104).

As mulheres que ingressam no mercado de trabalho se deparam com dificuldades. Percebe-se que poucas alcançam os cargos mais elevados da hierarquia, além de serem, em grande parte, destinadas a trabalhos tradicionalmente ligadas à atividade feminina: funções no setor de serviço, associadas à educação de crianças e jovens, cuidados da saúde, serviços de limpeza, trabalho social e comércio de mercadorias.

\section{O trabalho feminino na economia globalizada}

Não há como negar que o comportamento da mulher sofreu várias transformações nas últimas décadas, e uma das causas que favoreceram principalmente um maior desenvolvimento do trabalho da mulher fora de casa foi, sem dúvida, a criação da pílula anticoncepcional. Ela completou 50 anos em 2010, o seu surgimento contribuiu para mudança do pensamento e o comportamento da mulher na sociedade. Antes a mulher trabalhadora que se ausentava várias vezes devido à gravidez, a partir desse momento pode controlar o momento que deseja ter filhos. Com o avanço dos movimentos feministas que pressionavam para a criação de novas leis que defendessem as melhores condições de trabalho feminino houve uma mudança drástica do papel da mulher na sociedade. Pela primeira vez a escolha de engravidar, ou não, ficou nas mãos da mulher. Dessa possibilidade abrem-se novas oportunidades para a mulher: a decisão de quando procriar, a opção de retardar a maternidade em nome dos estudos e da carreira. 
Atualmente a mulher tende a adiar o casamento e a procriação para se dedicar aos estudos e carreira. Desde a década de 1980, observa-se a elevação da idade em que as mulheres se casam e essa tendência se acentua a partir da década seguinte 1990, segundo o IBGE, nas Estatísticas do casamento civil 1999/2008. Em 1999 a maioria das mulheres se casava dos 20 aos 24 anos, porém em 2008 percebemos que essa taxa de nupcialidade está mudando para 25 a 29 anos e está aumentando progressivamente a quantidade de mulheres que casam de 30 a 34 anos $^{3}$.

Ao que se refere à maternidade, um estudo do FEA-USP mostra que as trabalhadoras com filhos pequenos recebem em média 27\% menos que suas colegas sem filhos. Apesar de todos os avanços no Direito do Trabalho e proteção ao trabalho feminino, as mulheres continuam sendo alvo de preconceito, principalmente as mulheres com filhos menores. $\mathrm{O}$ afastamento compulsório, por imposição da maternidade, afasta a mulher dos cursos e de oportunidades no trabalho. (RODRIGUES, Ana. Ser mãe não é profissão. Revista Veja. São Paulo, maio 2010).

A maternidade não é a única dificuldade que a mulher encontra para alcançar a isonomia. É comprovado que as mulheres estudam mais que os homens, mas não se nota esse benefício nos salários quando avançam na carreira e envelhece. $\mathrm{Na}$ faixa dos 20 anos, a diferença salarial entre homens e mulheres, no mundo ocidental rico, é de apenas $6 \%$, segundo um levantamento da Cranfield University School of Management da Inglaterra. Com o aumento da idade da mulher essa diferença aumenta para $21 \%$. Há uma tendência da mulher em contar com a ajuda do

\footnotetext{
${ }^{3}$ Disponível em <http://www.ibge.gov.br/ibgeteen /mulher 2011 /\#\&panel1-5>. Acesso em: 29 jan. 2012
}

companheiro para fazer tarefas que antes eram exclusivas das mulheres, como cuidar do lar e dos filhos. (RODRIGUES, Ana. Ser mãe não é profissão. Revista Veja. São Paulo, maio 2010).

\section{Normas legais de proteção ao trabalho da mulher}

A Constituição Brasileira de 1988 se tornou um marco jurídico ao estabelecer pela primeira vez que os deveres e responsabilidades decorrentes da sociedade conjugal cabem igualmente a ambos os conjugues. Trata-se da quebra de um padrão jurídico que legitimava declaradamente a organização patriarcal e a consequente tendência a privilegiar o homem ante a mulher. Nessa ótica, o Direito do Trabalho que, antes, destinava-se a proteger o lugar da mulher no lar agora se destina a garantir a sua efetiva possibilidade de trabalhar. Em seu lugar apresenta-se uma ideologia de igualdade de direitos e deveres de ambos os gêneros. É um processo ainda em fase de consolidação.

Antes da Constituição de 1988, o Direito do Trabalho conservava às mulheres um caráter protecionista, proibia-se, por exemplo, que elas trabalhassem no período noturno ou que fizessem horas-extras. Com a nova Constituição esse caráter muda para promover às mulheres igualdade de oportunidades. (LOPES, Cristiane M. S. Direito do Trabalho da Mulher. Cadernos Pagu, Paraná, n. 26, p. 408-411. jan./jun. 2006). A regulamentação jurídica da trabalhadora, em diferentes países, ocupou-se principalmente da proteção da maternidade, com descansos obrigatórios maiores; proibição quer quanto à duração diária e semanal do trabalho, quer quanto a determinados tipos de atividades prejudiciais ao organismo do ser humano e que, portanto, deveriam ser reservadas apenas aos homens. (NASCIMENTO, 2011, p. 420) 
O direito promocional do trabalho da mulher surgiu quando as premissas que inspiravam a legislação proibitiva anterior caíram em desuso, e a mulher deixou de ser considerado um ser inferior que necessita $\mathrm{da}$ proteção do Estado, como se fosse incapaz das mesmas oportunidades de trabalho oferecidas pela sociedade ao homem. (NASCIMENTO, 2011, p. 420). Após a promulgação da Constituição Federal de 1988 iniciou-se o processo de adaptação às novas regras jurídicas, com a proibição da discriminação em relação ao sexo (art. $3^{\circ}$, inciso IV e art. $5^{\circ}$, inciso I da Constituição Federal) e abolição da "chefia" da família (art. 226, \5 $5^{\circ}$ da Constituição Federal) em que os direitos e deveres referentes à sociedade conjugal são exercidos igualmente pelo homem e pela mulher.

No âmbito civil, com efeito, o novo código se adequou ao mandamento constitucional, abolindo a noção de chefia da sociedade conjugal, proclamando que a direção da sociedade conjugal será exercida, em colaboração, pelo marido e pela mulher (art. 1567 do Código Civil). Além disso, a expressão "pátrio poder" antes utilizado no Código Civil de 1916 é substituída por "poder familiar". A finalidade do casamento deixa de ser a constituição da família, para ser definida como meio para estabelecer a comunhão plena de vida, com base na igualdade de direitos e deveres dos cônjuges (art. 1511 do Código Civil).

No âmbito trabalhista, o princípio da isonomia inspirou várias alterações legislativas, referentes às normas de proteção à maternidade nos âmbitos trabalhista $\mathrm{e}$ previdenciário (art. 392 e seguintes da CLT, art. 201, inciso II da CF com acréscimos da Lei 8213/91) e instituição de normas de combate à discriminação e meios de assegurar a igualdade, por exemplo, o $\int 7^{\circ}$, incisos I e II da Constituição Federal, que assegura que a mulher se aposente cinco anos mais cedo que o homem.
Para Cristiane Lopes, Procuradora do Trabalho e membro do Núcleo de Combate à Discriminação da CODIN/PR, referente à aposentadoria a Constituição Federal distingue homens e mulheres, com razão. Pois para o (a) trabalhador(a) poder contribuir tem que estar trabalhando. E para as mulheres é mais difícil manter uma vida produtiva linear, especialmente por conta $\mathrm{da}$ maternidade, são obrigadas a deixar de contribuir para a Previdência Social, pois têm de se afastar de seus empregos nos anos iniciais da criação dos filhos. (LOPES, Cristiane M. S. Direito do Trabalho da Mulher. Cadernos Pagu, Paraná, n. 26, p. 428. jan./jun. 2006).

A jornada do trabalho da mulher não difere da do homem. Em algumas atividades profissionais a lei fixa jornadas inferiores, não por causa do sexo, mas sim devido da natureza prejudicial ao ser humano, como é o caso de trabalho cuja principal atividade envolve a utilização do telefone.

No direito contemporâneo há também o contrato especial de emprego da mulher, para Amauri Nascimento, é especial o contrato de emprego que difere do contrato peno e duração indeterminada. A principal proteção do direito do trabalho da mulher é a proteção à gestante, os principais direitos referem-se à estabilidade da gestante e a licença-maternidade.

(NASCIMENTO, 2011, p. 415). As cláusulas das negociações coletivas que abordam o trabalho da mulher também são fontes de direito, e devem ser consideradas. Segundo pesquisa do DIEESE em 2001 cerca de 46\% das mulheres estavam inseridas no mercado de trabalho, porcentagem que aumenta a cada ano, favorecendo assim a elaboração de cláusulas específicas para o gênero.

Entre as cláusulas relativas ao trabalho feminino, SACC (Sistema de Acompanhamento de Contratações Coletivas) por meio do DIEESE destacou as 
seguintes: licença aborto, estabilidade aborto, garantia contra a discriminação, direito de trabalhar sentada, fornecimento de absorventes, proteção contra o assédio sexual, prevenção ao câncer ginecológico, liberação da gestante antes do término da jornada de trabalho, função compatível à gestante. (DIEESE. Negociação Coletiva e Equidade de Gênero no Brasil: cláusulas relativas ao trabalho da mulher 1996-2000. Pesquisa Dieese n. 17, p. 23, ago.2003). Quanto à estabilidade da gestante a legislação que serve de referência para essa garantia encontra-se nas Disposições Transitórias da Constituição Federal, art. 10, inciso II, b, que determina vedada a dispensa arbitrária sem justa causa da empregada gestante.

O dispositivo legal que ampara a normatização das condições ambientais e procedimentos para o desempenho da função da gestante encontra-se no $\int 4^{\circ}$ do art. 392 da Consolidação das Leis do Trabalho, modificado pela Lei 9799, de 26 de maio de 1999, que garante a transferência de função da gestante, quando as condições de saúde exigir, é assegurada a retomada da função anteriormente exercida, logo após o retorno da licença maternidade.

A Constituição Federal, no artigo $7^{\circ}$, inciso XVIII, garante às trabalhadoras a licença à gestante, sem prejuízo do emprego, com duração de 120 dias, conforme o artigo 392, da CLT, prorrogáveis por mais 60 dias, a critério e conta do empregador. Apesar do número restrito de unidade de negociação que pactuam cláusulas relacionadas às condições de trabalho da mulher, é importante registrar o aumento do número de negociações que tratam de dois assuntos específicos: assédio sexual e assédio moral.

Ampliou-se o número dessas negociações, no período de 2001-2006 o SACC por meio do DIESSE constatou que $10 \%$ unidades pesquisadas já se preocuparam com essa cláusula demonstrando assim uma tendência nessa área. (DIEESE. Negociação de Cláusulas de Trabalho Relativas à Igualdade de gênero e raça 2007-2009. Organização Internacional do Trabalho, p. 92, ago.2011).

O artigo 389 da CLT obriga as empresas a dispor de cadeiras ou bancos, que permitam às mulheres trabalhar sem grande esgotamento físico, instalar vestiário com armários privativos das mulheres, e o que se fizer necessário à segurança e conforto das mulheres.

A CLT, em seu artigo 395, garante em caso de aborto legal, comprovado por atestado médico oficial, repouso remunerado de duas semanas, ficando assegurado o direito de a trabalhadora retornar à função que ocupava antes do afastamento.

No artigo 461 da CLT, está previsto que, "sendo idêntica a função, a todo trabalho de igual valor, prestando ao mesmo empregador, na mesma localidade, corresponderá igual salário, sem distinção de sexo". Também na Constituição Federal regula sobre esse tema em seu artigo $7^{\circ}$, inciso XXX, no qual proíbe a diferença de salário, de exercício de função e de critério de admissão por motivo de sexo, idade, cor ou estado civil.

\section{A divisão sexual do trabalho e as relações sociais}

Atualmente a maioria do trabalho doméstico é realizado em sua maioria, pelas mulheres. A divisão do trabalho entre os homens e as mulheres é em primeiro lugar a imputação aos homens do trabalho produtivo e a dispensa do trabalho doméstico às mulheres, ao passo que são cada vez mais numerosas em nossa sociedade as mulheres que querem entrar e se manter no mercado de trabalho. 
Ao longo da história observa-se que o trabalho masculino é mais valorizado que o da mulher. Para Helena Hirata e Daniele Kergoat, sociólogas francesas, a divisão do trabalho é a base para as relações sociais de sexo. A divisão sexual do trabalho é o suporte empírico que permite a mediação entre relações sociais (abstratas) e práticas sociais (concretas). Em outros termos: elimine a imputação do trabalho doméstico às mulheres e as relações sociais desmoronam, junto com as relações de força, a dominação e o antagonismo que essas relações carregam. A divisão sexual do trabalho está no âmago do poder que os homens exercem sobre as mulheres. (MARUANI e HIRATA orgs, 2003, p.114).

Quando a divisão sexual do trabalho se transforma, evolui, e começa a possibilitar a igualdade de oportunidades, as relações sociais são diretamente afetadas e, em reflexo se desenvolve do mesmo modo.

No debate sociológico, ou a biologia é negada para melhor combater aqueles que naturalizaram as diferenças sexuais, ou tentase integrá-la na formação da ideia de gênero e na opressão masculina, evocando a força física dos homens, sua violência, como parte de sua supremacia, como faz Cynthia Cockburn. (COCKBURN, 1986 apud MARUANI e HIRATA orgs, 2003, p.120).

A segunda questão é a relação entre gênero e tecnologia. Trata-se de considerar o caráter sexuado dos trabalhos considerados técnicos na análise das diferenças entre os sexos. A ideia da construção social da incompetência técnica das mulheres veiculada pela sociologia e pela antropologia.

A psicodinâmica, porém, contribui de outra maneira, enriquecendo a análise sociológica do trabalho das mulheres introduzindo a questão da relação entre trabalho e saúde mental: o trabalho fragmentado, monótono e repetitivo em linhas de montagem, ou em trabalhos semelhantes, que se observa uma cadência imposta, é um trabalho destinado majoritariamente às mulheres. Ele se opõe às atividades tipicamente masculinas, caracterizadas por cooperação, autonomia, iniciativa, criatividade, atividades que dependem, conforme as sociólogas Helena Hirata e Daniele Kergoat gostam de definir como trabalhos estruturantes e sublimatórios. (MARUANI e HIRATA orgs, 2003, p.120).

A abordagem antropológica das relações familiares é diferente, ao dar prioridade à família, contrasta com a abordagem da psicodinâmica do trabalho. $\mathrm{Na}$ visão antropológica das relações familiares a questão de poder, ou relações de força, entre os sexos, que segundo Christophe Dejours, faz referência como "alquimia social", que seria o desprezo ao sofrimento, violência contra os mais fracos, considerados comumente um defeito, são valorizados como "qualidades viris" quando exercidas por homens em suas práticas de trabalho. (DEJOURS, 1998 apud MARUANI e HIRATA orgs, 2003, p.120).

Essas considerações são de suma importância, pois são alicerce da atual estrutura de pensamento em relação à divisão sexual do trabalho, e como ela interage com as relações sociais entre os sexos.

\section{A diferença salarial entre} gêneros

Nos últimos anos, cada vez mais mulheres tem ingressado no mercado de trabalho, por isso tem surgido estudos sobre as questões de gênero no mundo do trabalho, um dos assuntos discorridos é sobre a diferença salarial entre gêneros. Nesse contexto discute-se a convivência de um lado precário, composto por segmentos do mercado de trabalho tradicionalmente 
ocupados pelas mulheres, e um lado virtuoso, em franca ascensão, que inclui as posições mais prestigiosas, até agora prioritariamente ocupadas pelos homens, como as profissões de nível superior.

Nas ultimas décadas mulheres passaram a estudar mais, chegando a estudar mais que o homem. Segundo dados do INEP/MEC, em 2009, do total de concluintes do ensino médio, 55,6\% eram mulheres e, no ensino superior (graduação presencial), essa proporção chegava a 56,8\%, devendo crescer ainda mais.

Apesar disso a remuneração mensal por hora trabalhada da mulher é claramente inferior a do homem, conforme demonstra a tabela abaixo:

Rendimento médio mensal por hora dos ocupados, por sexo, segundo nível de escolaridade Região Metropolitana de São Paulo - 2000-2010

Em porcentagem

\begin{tabular}{|c|c|c|c|c|c|c|c|c|}
\hline \multirow{2}{*}{$\begin{array}{l}\text { Nivel de } \\
\text { escolaridade }\end{array}$} & \multicolumn{2}{|c|}{ Total } & \multicolumn{2}{|c|}{ Mulheres (A) } & \multicolumn{2}{|c|}{ Homens (B) } & \multicolumn{2}{|c|}{ Relação $(A) /(B)$} \\
\hline & 2000 & 2010 & 2000 & 2010 & 2000 & 2010 & 2000 & 2010 \\
\hline Total & 8,5 & 7,5 & 7,0 & 6,4 & 9,5 & 8,4 & 73,6 & 75,7 \\
\hline $\begin{array}{l}\text { Até ensino superior } \\
\text { incompleto }\end{array}$ & 6,2 & 5,6 & 4,9 & 4,6 & 7,0 & 6,3 & 69,9 & 72,7 \\
\hline $\begin{array}{l}\text { Ensino superior } \\
\text { completo }\end{array}$ & 26,2 & 20,0 & 20,4 & 15,7 & 31,4 & 24,6 & 65,2 & 63,8 \\
\hline
\end{tabular}

Fonte: SEP. Convênio Seade - Dieese e MTE/FAT. Pesquisa de Emprego e Desemprego - PED.

Essas informações evidenciam que completar o ensino superior, de fato, significa alcançar postos mais qualificados e mais bem remunerados. Embora isso ainda não garanta a isonomia na remuneração entre homens e mulheres. (Disponível em: http://www.dieese.org.br/ped/sp/mulherr m sp2011.pdf. Acesso em: 20 dez. 2011).

Um relatório apresentado à Conferência Internacional do Trabalho em 2009 apresentava que, na maioria dos países, o salário das mulheres por trabalho de igual valor representa, em média, entre $70 \%$ e $90 \%$ do salário dos homens, mas não é raro encontrar diferenças maiores. Em 2009, a Confederação Internacional dos Sindicatos (CIS) elaborou um relatório referente a 20 países ${ }^{4}$, que identificou uma diferença salarial

${ }^{4}$ África do Sul, Alemanha, Argentina, Brasil, Chile, República da Coréia, Dinamarca, Espanha, Estados Unidos, Finlândia, Hungria, Índia, Itália, México, Países Baixos, Paraguai, Polônia, Reino Unido, Federação Russa e Suécia. média de 22,4\% e uma diferença mediana de 20,4. Outro estudo feito pela CIS em 2010, que abrangia mais 23 países, revelou uma diferença salarial mediana global de $26 \%$ a favor dos homens. Segundo o relatório, a diferença é menor nas mulheres sem filhos $(20 \%)$ do que naquelas que tem filhos (32\%). (OIT. Igualdade no Trabalho: Um desafio contínu. Conferência Internacional do Trabalho $100^{\mathrm{a}}$, Portugal: Bureau Internacional do Trabalho Genebra, p. 24, maio. 2011).

De acordo com os dados divulgados pela OCDE (Organização para a Cooperação e o Desenvolvimento Econômico), em 2010, a diferença salarial mediana dos ganhos de trabalho de período integral era de 17,6\% nos seus países membros. Nos países cujos dados foram divulgados, a diferença atingia 40\% na República da Coréia e mais de $30 \%$ no Japão, e situava-se entre $20 \%$ e $25 \%$ na Alemanha, no Canadá e no Reino Unido, 
entre $15 \%$ a $20 \%$ na Austrália, na República Checa, na Espanha, nos Estados Unidos, na Finlândia, nos Países Baixos, em Portugal, na Suécia e na Suíça, entre $10 \%$ a $15 \%$ na Dinamarca, na França, na Grécia, na
Hungria e na Irlanda, sendo igual ou inferior a 10\% na Bélgica, na Nova Zelândia e na Polônia (dados da OCDE).

As conclusões da OCDE se encontram reproduzidas na figura 2.1.

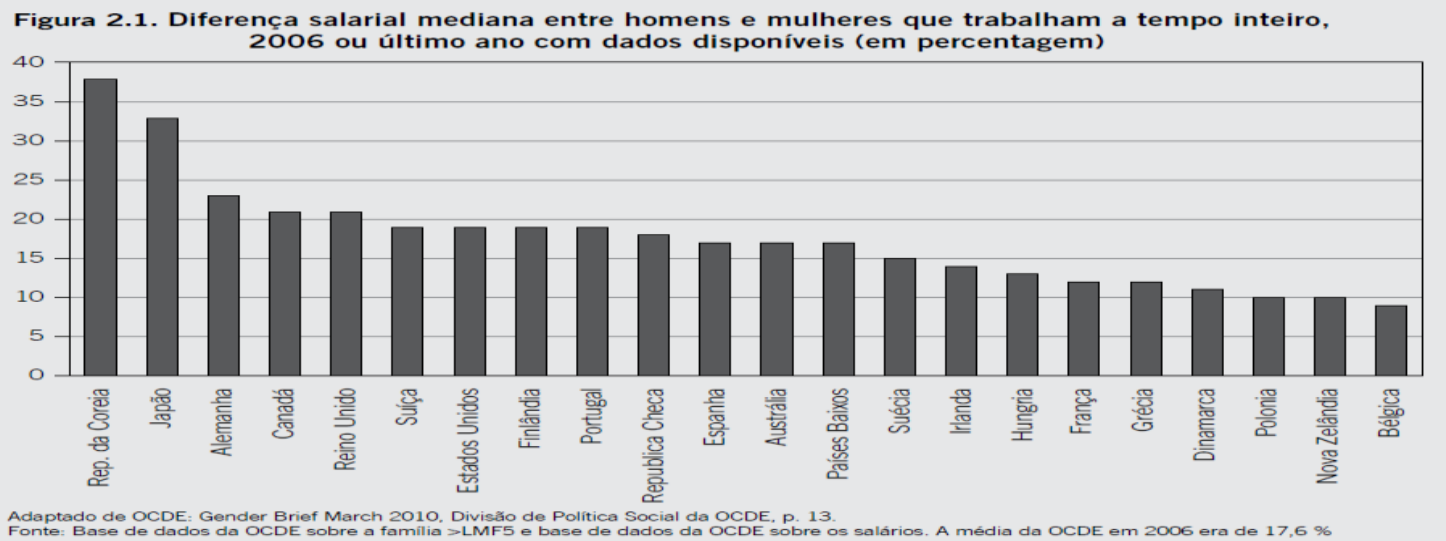

\section{A equiparação salarial}

A igualdade salarial manifestou-se no direito positivo do Brasil com a revolução de 1930, por meio do Decreto 20.261, de 29 de julho de 1931, que estabeleceu proibição de maior salário ao estrangeiro. Depois, foi ampliada pelo Decreto 21.417, de 17 de maio de 1932, que regulava condições de trabalho das mulheres nas indústrias e comércios. A Constituição de 1934, artigo 121, \ $1^{\circ}$, acolheu o princípio e aumentou seu campo de aplicação, proibindo a diferenciação salarial com base na idade, sexo, nacionalidade ou estado civil. Porém, foi omitida pela Constituição de 1937, mas a legislação ordinária a sustentou, por meio da CLT de 1943. Retornou ao plano constitucional de 1946, mantendo-se na Constituição de 1967, com a proibição de diferenças de salários e de critérios de admissão por motivo de sexo, cor, estado civil, mas suprimida a idade com fator positivo da distinção remuneratória. (NASCIMENTO, 1968, p. 222)

A Constituição Federal de 1988 adotou o princípio de igualdade de direitos, todos os indivíduos tem o direito de tratamento idêntico pela lei, em consonância com os critérios acolhidos pelo ordenamento jurídico.

O Princípio da Igualdade é o fundamento principal na análise da equiparação salarial. A origem histórica da equiparação salarial vem do art. 427 do Tratado de Versalhes que estabeleceu o seguinte princípio "salário igual, sem distinção de sexo, para trabalho igual em quantidade e qualidade". A Organização Internacional do Trabalho de 1919 no art. 41 prevê "salário igual, sem distinção de sexo, para trabalhos de igual valor".

A Declaração Universal dos Direitos Humanos de 1948, em seu artigo 23, estabelece que "toda pessoa tem direito, sem nenhuma discriminação, a um salário igual 
para um trabalho igual". Elevada a princípio constitucional, o Art. $7^{\circ}$ da Constituição Federal, prescreve no inciso XXX que é vedada a "diferença de salários, de exercício de funções e de critério de admissão por motivo de sexo, idade, cor ou estado civil".

A CLT regula os critérios pelos quais a equiparação salarial é considerada pelo ordenamento jurídico, o Art. 461 prevê tais requisitos.

Todo empregado que exerce trabalho de igual valor deve receber remuneração igual, sem distinção de gênero, conforme prescreve o art. $5^{\circ}$ da CLT. Os requisitos da equiparação salarial são: função semelhante, de mesmo valor, mesma produtividade, mesma perfeição técnica, simultaneidade na prestação de serviços, mesmo empregador, mesma localidade. Todas essas exigências encontram-se estabelecidas no artigo $461 \mathrm{da}$ mesma Consolidação (informação da CLT).

\section{Causas que impedem a equiparação salarial}

São várias as causas que impedem a equiparação salarial efetiva, entre elas estão em destaque: a evidente falta de divulgação pelos meios de comunicação do direito à equiparação salarial; e a falta de continuidade de tempo de serviço das mulheres em decorrência dos filhos e a dificuldade do levantamento de provas devido o restrito acesso à informação dos salários praticados na empresa.

A primeira causa é a maternidade, pois afeta o engajamento da mulher no mercado de trabalho. Pois ao ausentar-se para cuidar dos filhos pequenos ela perde a continuidade na prestação de serviços dificultando o alcance dos elementos necessários para a isonomia salarial. A tendência observada atualmente é que as mulheres estão postergando a gravidez, constata-se que as que postergam a gravidez tem melhor inserção no mercado de trabalho.

A segunda causa é a falta de publicidade do assunto. Segundo levantamento realizado pela ANDI - Comunicação e Direitos e pelo Instituto Patrícia Galvão no âmbito do Observatório Brasil da Igualdade de Gênero (Eixo Comunicação e Mídia) da Secretaria de Políticas para Mulheres da Presidência da República, a imprensa brasileira deixou para segundo plano questões referente à desigualdade de salários entre homens e mulheres, cerca de $91 \%$ dos textos não trazem o assunto como pauta. A ausência do debate sobre a desigualdade salarial impede que as mulheres comuns não tenham acesso a essa informação, desconhecendo assim que tem o direito à isonomia salarial. (Disponível em<http://www.andi.org.br/sites/default/f iles/resumo_executivo_mulher_trabalho.pdf $>$ Acesso em: 06 fev. 2012)

A terceira causa que impede a equiparação salarial é a dificuldade de conseguir provas, devido ao sigilo salarial.

\section{Levantamento de provas}

O ônus da prova do pagamento desigual de gênero é do autor da ação, ao passo que à defesa cabe à prova dos fatos modificativos, impeditivos e extintivos do pleito equiparatório (art. 818 da CLT e 333 do CPC; Enunciado $n^{\circ} 68$ TST). A dificuldade que pode surgir, concretamente, situa-se no tocante a precisa identificação de tais fatos. É do empregador o ônus da prova do fato impeditivo, modificativo ou extintivo da equiparação salarial. (ex- Súmula n 68 - RA 9/1977, DJ 11/02/1977).

Os fatos constitutivos são aqueles que, no seu conjunto, formam o tipo legal requisitado pela norma. No que diz respeito à equiparação, os elementos são: identidade de função, identidade de empregador, 
identidade localidade, simultaneidade no exercício funcional.

Os fatos que impediriam a equiparação quer modificando seus efeitos jurídicos originalmente cabíveis, quer impedindo esses efeitos compõem tais fatos: diferença de perfeição técnica na realização do trabalho, diferença de produtividade no tocante a essa realização laboral, diferença de tempo de serviço na função não superior a dois anos, existência de quadro de carreira na empresa, com promoções alternadas por merecimento e antiguidade, ocupação de função em decorrência de readaptação previdenciária por deficiência física ou mental. (GODINHO, 2002, p. 775)

$\mathrm{Na}$ ação de equiparação salarial, a prescrição é parcial e só alcança as diferenças salariais vencidas no período de cinco anos que precedeu o ajuizamento. (ex-Súmula $\mathrm{n}^{\circ}$ 274 - alterada pela Res. 121/2003, CJ 21/11/2003).

\section{Pena aplicada aos empregadores que infringem a isonomia salarial}

Não há um órgão específico que fiscaliza as empresas para prevenir e punir as empresas que praticam a diferenciação salarial entre gêneros. Sendo assim, caso existam salários desiguais para os empregados que exercem a mesma função, aqueles empregados que recebem menores salários deverão requerer na Justiça do Trabalho o pagamento das diferenças entre estes salários.

Em 06 de março de 2012 foi aprovado pelo Senado Federal, projeto de lei (Projeto de Lei da Câmara no 130 de 2011) que proíbe salários diferentes entre homens e mulheres que desempenham o mesmo cargo em uma empresa. Aceita por unanimidade e em caráter terminativo, a proposta visa a intensificar a proibição já exposta pela Constituição Federal e na CLT.

O texto estabelece que o empregador que descumprir a lei deverá pagar à funcionária multa equivalente a cinco vezes a diferença constatada durante o período de exercício da função. A ementa descreve que se acrescenta o $\int 3^{\circ}$ ao art. 401 da Consolidação das Leis do Trabalho, aprovada pelo Decreto-Lei $\mathrm{n}^{\circ} 5.452$, de $1^{\circ}$ de maio de 1943, a fim de estabelecer multa para combater a diferença de remuneração verificada entre homens e mulheres no Brasil. (Disponível em $<$ http://www.senado.gov.br/atividade/mat eria/detalhes.asp?p_cod_mate $=103844>$ Acesso em 09 abr. 2012)

\section{Considerações Finais}

A diferença salarial entre gêneros no ambiente laboral fere o Princípio da Isonomia. Procurou-se no presente texto levantar essas questões referentes ao princípio mencionado e suas consequências no Direito do Trabalho, visto que esse princípio é um dos principais alicerces de nossa Constituição Federal, pois permeia em todo ordenamento jurídico e tem como propósito equiparar o tratamento dispensado nas relações sociais, seja entre gêneros, raças ou credos diferentes.

As questões inicialmente apresentadas foram satisfatoriamente respondidas, destacou-se que o trabalho masculino é mais valorizado que o feminino, essa diferenciação tem raízes históricas, sociológicas e culturais. Os principais argumentos para prática dessa diferença, segundo sociólogos do séc. XX são os seguintes: a aparente fragilidade física da mulher em relação ao homem; a vontade divina que a mulher ficasse dentro do lar cuidando dos filhos, enquanto o homem fizesse trabalhos mais valorizados fora do 
lar: e o argumento referente à sombra da prostituição, segundo a lógica da época, a mulher que trabalhava se submetia à vontade de seu chefe, pois dele dependia para seu sustento.

De tudo que restou exposto na presente pesquisa, pode-se ressaltar principalmente que a Constituição Federal Brasileira, com base no Princípio da Isonomia, prescreve em seu art. $5^{\circ}$ que todos são iguais perante a lei e proibindo a prática da diferença salarial com base no gênero. Na CLT, o art. 461 cita os elementos necessários para a igualdade salarial, o indivíduo que se sentir lesado poderá levantar as provas necessárias para fazer valer seu direito.

Porém, apesar de todo esse aparato legal, pesquisas recentes ainda apontam que indivíduos de gêneros diferentes, mesmo exercendo trabalho de mesmo valor, com a mesma função, subordinados ao mesmo empregador, na mesma localidade simultaneamente; recebem salários diferentes, em todos esses casos com a mulher recebendo o menor valor.

As causas que impedem a equiparação salarial são várias, entre elas destacamos a falta de divulgação desse direito à população, a falta de continuidade de tempo de serviço das mulheres que se afastam do trabalho para cuidar dos filhos menores e a dificuldade do levantamento de provas devido ao restrito acesso às informações dos salários praticados na empresa.

Observou-se também que a equiparação salarial é uma preocupação mundial. A ONU (Organização das Nações Unidas) e a OIT (Organização Internacional do Trabalho) tem levantado essa questão e exigido que seus Estados membros tomem providências para diminuir esse quadro.

As causas da discriminação entre homens e mulheres têm raízes sociais profundas que não conseguirão ser removidas instantaneamente. Além da legislação específica se faz necessário um compromisso abrangente, entre o Estado, as empresas e a população. Requer um esforço persistente e prolongado da sociedade como um todo, para que, por exemplo, desde a infância meninos e meninas tenham a mesma criação, com as mesmas exigências sociais.

É necessária a interação dos gêneros por meio de vários programas e políticas nacionais, esse será, provavelmente, o meio mais eficaz de alcançar este objetivo, para evitar a discriminação, o pré-conceito, os paradigmas pré-concebidos passados e reforçados a cada geração.

A isonomia será alcançada por meio de um processo de análise dos efeitos da desigualdade material na vida cotidiana das mulheres e dos homens. É necessária a avaliação crítica da legislação com vistas à implementação de políticas públicas e programas específicos de promoção à igualdade. Trata-se de avaliar as preocupações e as experiências das mulheres e dos homens desde a elaboração, execução, acompanhamento até avaliação dessas políticas e programas, em todas as esferas políticas, jurídicas e sociais; de modo a assegurar vantagens e oportunidades iguais para mulheres e homens e evitar, deste modo, que a desigualdade seja perpetuada

\section{Referências Bibliográficas}

1. ALKMIM, Marcelo. Curso de Direito Constitucional. Florianópolis: Conceito Editorial, 2009.

2. ARISTÓTELES. Metafísica (livro I e II), Ética a Nicômaco e Poética. Trad. Leonel Vallandro e Gerd Bornheim da versão inglesa de W. D. Ross. São Paulo: Abril Cultural, 1984. 
3. ARAÚJO, L. A. D.; NUNES Jr., VIDAL

S. Curso de Direito Constitucional. $6^{\mathrm{a}}$ ed. São Paulo: Saraiva, 2002

4. ÀVILA, Humberto. Teoria dos Princípios: da definição à aplicação dos princípios jurídicos. $12^{\mathrm{a}}$ ed. São Paulo: Malheiros Editores, 2007.

5. BARBOSA, Rui. Oração aos Moços. $5^{a}$ ed. Rio de Janeiro: Edições Casa de Rui Barbosa, 1997.

6. BONAVIDES, P. Curso de Direito Constitucional. $18^{a}$ ed. São Paulo: Malheiros Editores, 2006.

7. CALIL, Léa Elisa Silingowschi. História do Direito do Trabalho da Mulher: aspectos históricos - sociológicos do início da República ao final deste século. São Paulo: LTr., 2000.

8. DELGADO, Mauricio Godinho. Curso de Direito do Trabalho. São Paulo: LTr., 2002.

9. DELGADO, Didice G; CAPPELIN, Paola; SOARES, Vera (orgs.). Mulher e Trabalho experiências de ação afirmativa. São Paulo: Boitempo Editorial, 2004.

10. DIEESE. A Situação do Trabalho no Brasil. São Paulo: DIEESE, 2001.

11. EMÍLIO, Marli e TEIXEIRA, Marilane e NOBRE, Miriam e GODINHO, Tatau (orgs.) Trabalho e Cidadania Ativa para as Mulheres: desafios para as Políticas Públicas. São Paulo: Prefeitura Municipal de São Paulo - Coordenadoria Especial da Mulher, 2003.

12. KELSEN, Hans. O problema da justiça. $3^{\mathrm{a}}$ ed. São Paulo: Martins Fontes, 1998.

13. MAGANO, O. Bueno. ABC do Direito do Trabalho. $2^{a}$ ed. São Paulo: Editora dos Tribunais, 2000.
14. MARQUES, Fabíola. Equiparação Salarial por Identidade no Direito do Trabalho Brasileiro. São Paulo: LTr, 2001.

15. MARTINS, Sergio Pinto. Direito do Trabalho. 24a ed. São Paulo: Atlas, 2008.

16. MARUANI, Margaret e HIRATA, Helena (orgs.). As Novas Fronteiras da Desigualdade: homens e mulheres no mercado de trabalho. São Paulo: Editora SENAC. 2003.

17. MELlO, Celso Antônio Bandeira. O Conteúdo Jurídico do Princípio da Igualdade. $3^{\mathrm{a}}$ ed. São Paulo: Malheiros Editores, 2010.

18. MICHELET, Jules. A Mulher. São Paulo: Martins Fontes, 1995.

19. MONTORO, André Franco. Introdução à Ciência do Direito. 26 $6^{\mathrm{a}}$ ed. São Paulo: Editora Revista dos Tribunais, 2006.

20. MORAES, Alexandre de. Direito Constitucional. $17^{\mathrm{a}}$ ed. São Paulo: Atlas, 2005.

21. NASCIMENTO, Amauri Mascaro. Direito Contemporâneo do Trabalho. São Paulo: Saraira, 2011.

22. NASCIMENTO, Amauri Mascaro. Iniciação ao Direito do Trabalho. $27^{\mathrm{a}}$ ed. São Paulo: Ltr, 2001.

23. NASCIMENTO, Amauri Mascaro. O Salário. São Paulo: Ltr, 1968.

24. SILVA, José Afonso da Silva. Curso de Direito Constitucional Positivo. 21 ${ }^{\mathrm{a}}$ ed. São Paulo: Malheiros Editores, 2002.

25. SULLEROT, E. História e Sociologia da Mulher no Trabalho. São Paulo: Ed Expressão, 1968.

26. VIEIRA, Oscar Vilhena. Direitos Fundamentais, uma leitura da jurisprudência do STF. São Paulo: Malheiros Editores, 2006. 